Annette Rehrl · Illustrierte Ausgaben von Goethes Lyrik 1800 - 1933 


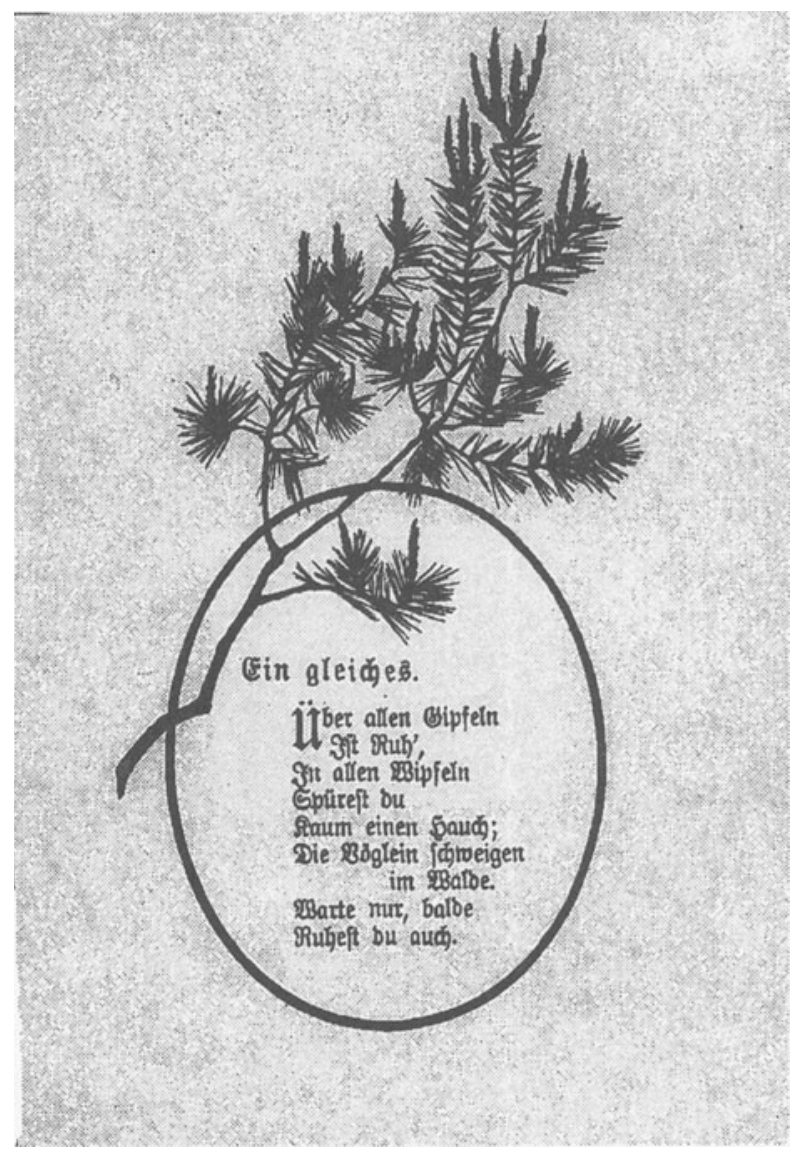

Silhouette von Johanna Beckmann, 1909 


\section{Annette Rehrl}

\section{Illustrierte Ausgaben von Goethes Lyrik 1800 - 1933}


Die Deutsche Bibliothek - CIP-Einheitsaufnahme

Rehrl, Annette:

Illustrierte Ausgaben von Goethes Lyrik 1800 - 1933 /

Annette Rehrl.

- Stuttgart : $M$ und P, Verl. für Wiss. und Forschung, 1996

Zugl.: München, Univ., Diss., 1993

NE: HST

ISBN 978-3-476-45136-1

ISBN 978-3-476-45136-1

ISBN 978-3-476-04232-3 (eBook)

DOI 10.1007/978-3-476-04232-3

Dieses Werk ist einschließlich aller seiner Teile geschützt. Jede Verwertung außerhalb der engen Grenzen des Urheberrechtsgesetzes ist ohne Zustimmung des Verlages unzulässig und strafbar. Das gilt insbesondere für Vervielfältigungen, Übersetzungen, Mikroverfilmungen und Einspeichenung in elektronischen Systemen.

M \& $\mathbf{P}$ Verlag für Wissenschaft und Forschung ein Verlag der J.B. Metzlerschen Verlagsbuchhandlung und Carl Emst Poeschel Verlag GmbH in Stuttgart

(C) 1996 Springer-Verlag GmbH Deutschland Ursprünglich erschienen bei J.B. Metzlersche Verlagsbuchhandlung und Carl Ernst Poeschel Verlag GmbH in Stuttgart 1996 


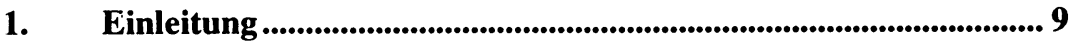

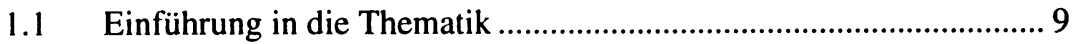

1.2 Forschungsüberblick ................................................................... 14

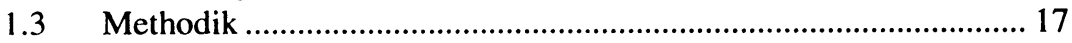

2. Lyrikillustration im Rahmen der Buchgeschichte ..................... 21

2.1 Entwicklung von Illustrationstechniken und Druckverfahren ........ 21

2.2 Erscheinungsformen der Lyrikillustration im Kontext der Buchkunst ............................................................ 27

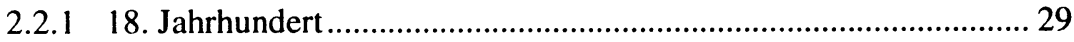

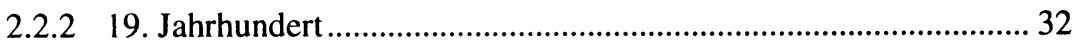

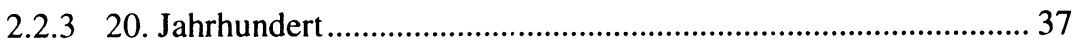

2.3 Funktionen der Lyrikillustration im Wandel der Epochen .............. 40

2.4 Zum Verhältnis von Wort und Bild ................................................. 45

3. Funktionen der Illustration in Goethe-Gedichtausgaben ........... 55

3.1 Form und Wirkung:

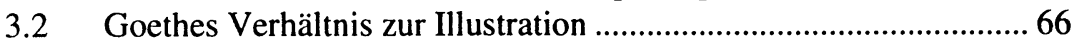

$3.3 \quad$ Verlegerinteressen ....................................................................... 78

3.4 Zielgruppenorientierte Editionen ..................................................... 89

4. Die Illustrationen zu J. W. Goethes Lyrik ..................................... 99

4.1 Illustrierte Gedichtabteilungen (Tab. 1, 2) .................................. 101

4.2 Die illustrierten Gedichte (Tab. 3) ………..................................... 109

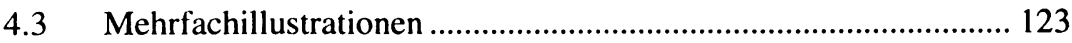

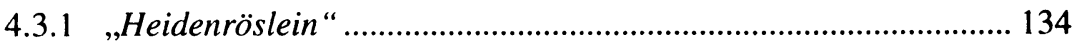

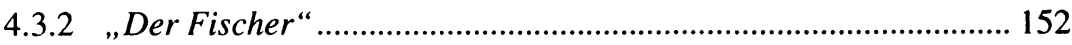

4.3.3 „Der Totentanz “ ............................................................................ 170

5. Die illustrierten Gedichtausgaben ............................................... 181

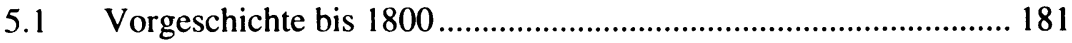

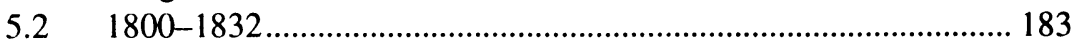

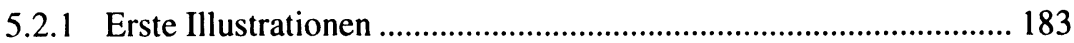

5.2.2 'Kupfer-Sammlung zu Goethes sämmtlichen Werken ' ................. 189

5.2.3 Almanache und Taschenkalender .............................................. 190

5.2.4 Eugen Napoleon Neureuthers 'Randzeichnungen zu Goethes Balladen und Romanzen ‘ ............................................................. 195

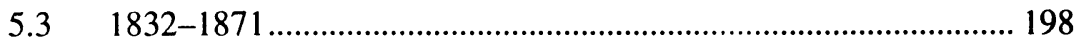

5.3.1 Wilhelm Kaulbachs 'Gallerie zu Goethe's sämmtlichen Werken' 199

5.3.2 Das 'Goethe Album ‘ von Ludwig Richter ................................... 202 


\section{Inhaltsverzeichnis}

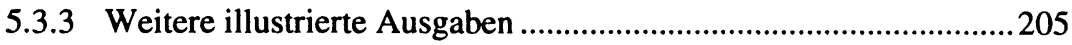

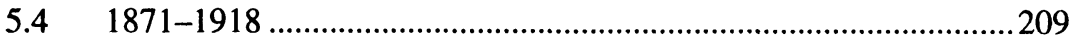

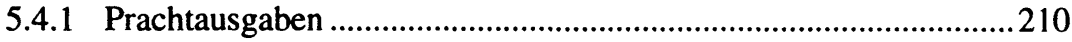

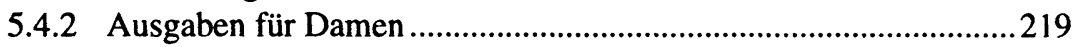

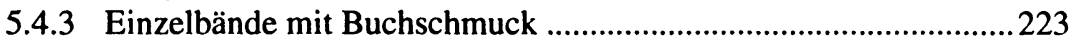

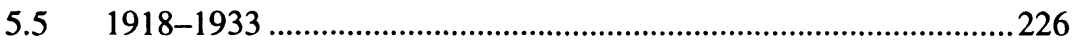

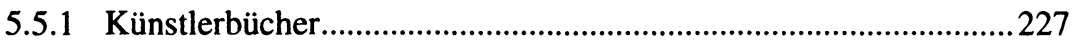

5.5.2 'Goethe-Gedichte' bei Paul Cassirer ............................................2231

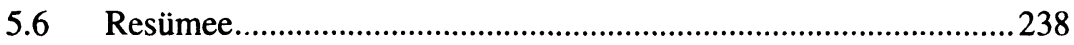

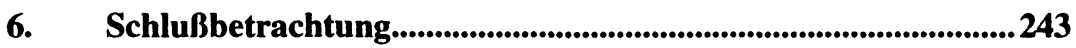

Anhang........................................................................................................ 247

Verzeichnis illustrierter Goethe-Lyrikausgaben in chronologischer

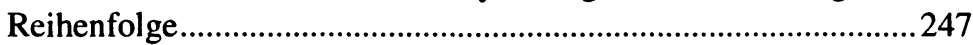

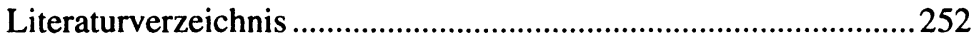




\section{Vorwort}

Statt eines Vorworts möchte ich an dieser Stelle ausdrücklich all jenen danken, ohne die dieses Buch nie entstanden wäre.

Den Umstand, Johann Wolfgang Goethe als sporadischen, doch stets präsenten „Begleiter“ gewonnen zu haben, verdanke ich meinem Doktorvater, Herrn Prof. Dr. Günter Häntzschel von der LudwigMaximilians Universität München. Er hatte die Idee zu diesem Thema und die Geduld, mich auch über Jahre der Berufstätigkeit hinweg mit viel Zuversicht zu betreuen.

Für sachdienliche Hinweise danke ich Frau Cornelia Banzhaf, M.A. und Dr. Georg R. Schroubek für wertvolle Anregungen. Er half, bedrohliche Klippen zu umschiffen und bewahrte mich vor dem Fall in manchen Abgrund.

Dank auch meinen Freunden, die des Themas nicht überdrüssig wurden und die Entstehung dieses Buches mit Interesse und Anteilnahme begleitet habe. Sie waren das heilsame Gegengewicht zu den Überstunden am Schreibtisch. Einem von ihnen, Rainer Kürvers, sei ganz besonders gedankt. Er stellte mir nicht nur die technischen Mittel zur Verfügung, sondern investierte viel Zeit, Freude und Geduld in die Erstellung dieses Buches.

Mögen sich darüber hinaus meine Eltern und all jene, die mich auf ihre Weise unterstützt haben, in diesem Dank eingeschlossen fühlen. 